\title{
So you want to do a psychology PhD? Tips for navigating the doctoral application process
}

\author{
Graham R Thew ${ }^{1,2}$ \\ ${ }^{1}$ Oxford Centre for Anxiety Disorders and Trauma, Department of Experimental Psychology, \\ University of Oxford \\ ${ }^{2}$ Oxford University Hospitals NHS Foundation Trust
}

\section{Introduction}

Many people may be interested in doing a psychology $\mathrm{PhD}$, but applying and obtaining a place to do this can be a difficult process to navigate. It can be hard to know where to start, so here l've summarised some thoughts and suggestions based on my own experience and those of colleagues and supervisors l've worked with. So whether you are an undergraduate or masters student, a health professional looking to develop their research skills, or someone coming from a different field or career altogether, I hope this may be of use.

I am focusing on 'traditional' psychology PhDs here, so I should note that some programmes, such as the professional doctorates in clinical, counselling, educational or forensic psychology, follow slightly different routes. However, the first two sections below may still apply to the research components of these courses.

I would welcome any feedback on this - if this has been useful to you, or if you think there is something that should be added or needs elaborating feel free to get in touch.

Fundamentally, to start a psychology PhD there are four things you need: 1) An idea, 2) A supervisor, 3) A course offer, and 4) funding. These are discussed below.

\section{1: An Idea}

Firstly, you'll need an idea of the general topic or research questions you want to focus on. Remember that this is going to be your main focus for the next few years, so it needs to be something that really interests you. At the early stage, you don't necessarily need to have anything too specific in mind, and there's perhaps an advantage to being flexible as this allows you to develop the idea through back-and-forth discussions with potential supervisors ${ }^{1}$.

\footnotetext{
${ }^{1}$ If you already have a specific supervisor or team in mind, you might choose to approach them first and develop your ideas entirely from there.
} 
It's useful to think about what the research gaps are in your chosen field, and what types of project would therefore help to address these - bear in mind there are often multiple ways to study the same question or topic. You can choose a topic that breaks entirely new ground, but it can help to have at least something you can build on (e.g. existing methodologies, measurement tools, some other researchers doing similar things who you could contact). Remember that a PhD is also about your development as a researcher, so if there are particular skills or techniques you want to learn, consider how you can factor these in.

Eventually you'll need to form the idea into a more structured set of plans that will form the proposal to include on your application. The planned studies will of course vary widely depending on the topic and methods used, but often this takes the form of three or four linked projects that would be manageable to complete in the timeframe (usually 3 years if working full time), and feasible in terms of data collection, participant recruitment etc. It's worth noting that the projects you propose here are not set in stone and will evolve over the course of the PhD.

\section{2: A Supervisor}

Once you have an idea or topic area in mind, the next step is to consider potential supervisors. This needs to be someone with the relevant expertise, interest, and time to mentor you and guide your work, and you'll be working with them closely over the next few years, so take the time to consider different options. You may want to contact other people in the same team, or their current doctoral students to find out more.

When you've identified someone that might be suitable, contact them to find out if they are taking on new students - if they're not, they may still be able to give you good recommendations about other potential supervisors. Hopefully they'll be interested and you can arrange a time to meet/speak to discuss your ideas and see whether you both would want to move towards making an application. Remember that the topic needs to align with their research interests too so keep open to new things they might suggest. Linking at least some of your proposed work into their current research topics can be helpful, as it will keep them interested in your work, and may provide opportunities to work with their collaborators.

Next, you'll need to formalise the ideas and planned projects in a written proposal. Your potential supervisor will be a good source of guidance here, so make sure to ask them about potential methodology, the feasibility of the projects, the practicalities involved and what resources you might need, so you can include these details. If you 
are looking to do the PhD part-time ask them if this would be an option. They'll also be a good source of information on funding (see section 4).

\section{3: A Course Offer}

Once you've done your preparation, you'll need to formally apply for a place on the doctoral programme at the university or research institution where your potential supervisor is based. Universities may offer different doctoral programmes in psychology ${ }^{2}$, so explore the options and ask for advice if needed. Check the deadlines closely, as its these that will determine the timeline for the whole process. Give yourself enough time to develop the proposal with your potential supervisor, and to write the application - you may want to go through several drafts to develop it fully.

As with any job or course application, the usual advice applies: read the requirements and procedures carefully, ask people to look at the application (especially your potential supervisor), and be sure to showcase both your academic achievements and your experience of the research process (e.g. publications, involvement in research projects, talks etc.). You may be invited to attend an interview, which sometimes involves giving a short presentation (e.g. about your academic career to date, a previous research project, or your proposed research) so prepare carefully and take opportunities to practise with someone else beforehand.

\section{4: Funding}

The final hurdle is obtaining funding to cover the course fees and your stipend/salary. Your funding may also cover research and/or travel expenses but this is variable. Getting the combination of a course offer and funding is often difficult; these sometimes come together as a package, or you may have to do an independent funding application. Typically, funding comes from national research councils, charities and trusts, industry, government organisations, or from universities themselves. There may also be specific funding programmes for studying abroad. Ask your potential supervisor for their recommendations of suitable funding bodies to apply to. You can also often contact funders directly for advice or queries.

\footnotetext{
${ }^{2}$ Some PhD programmes exist specifically for applicants who have already completed clinical training (either in clinical psychology or other healthcare disciplines), and who are looking to develop their research experience. Often these allow for the continuation of some clinical practice during the PhD.
} 


\section{Resources}

Advertised PhD positions

These generally have a broad topic in mind, so may be useful if you're looking for ideas. Some of these come with funding attached.

https://www.findaphd.com/

https://www.jobs.ac.uk/

https://www.phdportal.com

\section{Funders}

There are many different funders, ranging in size and therefore the number of students they support. Some cover all areas of psychology, while others only fund PhDs in a certain area, so check their remit. Rather than list funders here, I will recommend the link below which provides an excellent overview of different options.

\section{https://www.findaphd.com/funding/}

\section{Acknowledgements}

Thanks to Aneta Zarska and Sharif El-Leithy for getting me started on this, and to Milan Wiedemann, Gaby Tyson, and David M Clark for helpful comments. GRT is supported by the Wellcome Trust [102176]; and by the NIHR Oxford Biomedical Research Centre. The views expressed are those of the author(s) and not necessarily those of the NHS, the NIHR or the Department of Health.

\section{Contact}

Email: graham.thew@psy.ox.ac.uk

Twitter:@drgrahamthew 